\title{
Controle de Alternaria solani em Tomateiro por Extratos de Curcuma longa e Curcumina - I. Avaliação in vitro
}

\author{
María I. Balbi-Peña ${ }^{1}$, Andrea Becker ${ }^{1}$, José Renato Stangarlin¹, Gilmar Franzener ${ }^{1}$, Mário C. Lopes ${ }^{1}$ \\ \& Kátia R. F. Schwan-Estrada ${ }^{2}$
}
${ }^{1}$ Centro de Ciências Agrárias, Universidade Estadual do Oeste de Paraná - Unioeste, Campus de Marechal Cândido Rondon, Cx. Postal 1008, CEP 85960-000, Marechal Cândido Rondon, PR, e-mail: jrstangarlin@unioeste.br;
${ }^{2}$ Departamento de Agronomia, Universidade Estadual de Maringá, CEP 87020-900, Maringá, PR

(Aceito para publicação em 03/07/2006)

Autor para correspondência: José Renato Stangarlin

BALBI-PEÑA, M.I., BECKER, A., STANGARLIN, J.R., FRANZENER, G; LOPES, M.C. \& SCHWAN-ESTRADA, K.R.F. Controle de Alternaria solani em tomateiro por extratos de Curcuma longa e curcumina - I. Avaliação in vitro. Fitopatologia Brasileira 31:310-314. 2006.

\begin{abstract}
RESUMO
A descoberta de compostos secundários de plantas medicinais com atividade antimicrobiana mostra-se promissora para o controle de fitopatógenos. A cúrcuma, Curcuma longa, apresenta em seus rizomas compostos com atividade antifúngica. Assim, o objetivo deste trabalho foi avaliar a fungitoxidade in vitro dos extratos de cúrcuma e da curcumina contra Alternaria solani. Foram utilizados extratos brutos aquosos (EB) de rizomas de cúrcuma (esterilizados por autoclavagem) nas concentrações de $0,1,5,10$ e $20 \%$ e curcumina nas concentrações de 0, 50, 100, 200 e $400 \mathrm{mg} / \mathrm{L}$, os quais foram incorporados em meio de cultura batata-dextrose-ágar para avaliação de crescimento micelial e esporulação do fungo. Também foram testados extratos de cúrcuma a 10 e 15\% esterilizados por filtração. O efeito dos extratos de cúrcuma autoclavados e não autoclavados e da curcumina na germinação de esporos in vitro foi também avaliado. Os extratos de cúrcuma a 10 e $15 \%$ não autoclavados inibiram em 38,2\% e 23,2\%, respectivamente, o crescimento micelial e $71,7 \%$ e $87 \%$, respectivamente, a esporulação do fungo. Quando autoclavados, não apresentaram inibição do crescimento micelial nem da germinação de esporos e a inibição da esporulação foi menor, indicando a presença de compostos antimicrobianos termolábeis. O extrato não autoclavado na concentração de 5\% inibiu em até $15 \%$ a germinação dos esporos. A curcumina inibiu o crescimento micelial em $29,5 \%$ na maior concentração testada, sem, contudo, afetar a esporulação e a germinação de esporos in vitro. Esses resultados indicam o potencial antifúngico da cúrcuma e curcumina contra $A$. solani.
\end{abstract}

Palavras-chave adicionais: planta medicinal, cúrcuma, extrato de planta, pinta preta do tomateiro, controle alternativo de doenças de plantas.

\begin{abstract}
Control of Alternaria solani in tomato by Curcuma longa extracts and curcumin - I. In vitro evaluation

The discovery of plant secondary compounds with antimicrobial activity is very promising. Turmeric, Curcuma longa, has compounds in its rhizomes with fungicidal activity. The objective of this study was to evaluate the in vitro fungitoxic activity of turmeric extracts and curcumin against Alternaria solani. Four different concentrations $(0,1,5$, 10 and $20 \%$ ) of aqueous extracts of turmeric rhizomes (sterilized by autoclave) and four curcumin solutions $(0,50,100$, 200 and $400 \mathrm{mg} / \mathrm{L}$ ) were incorporated into potato dextrose agar medium in order to evaluate fungal mycelial growth and sporulation. To evaluate the effect of using an autoclave, $10 \%$ and $15 \%$ turmeric extracts were sterilized by filtration. The effects of autoclaved and non-autoclaved turmeric extracts and curcumin on in vitro spore germination were tested. The concentrations of 10 and $15 \%$ of non-autoclaved turmeric extracts inhibited the mycelial growth by $38.2 \%$ and $23.2 \%$ respectively and the fungal sporulation by $71.7 \%$ and $87 \%$ respectively. When turmeric extracts were autoclaved, neither mycelial growth nor spore germination was inhibited and the effect on sporulation was reduced, suggesting the presence of thermolabile antimicrobial compounds. The non-autoclaved 5\% extract inhibited spore germination by up to $15 \%$. At the highest concentration, the curcumin solution inhibited mycelial growth by $29.5 \%$. Neither in vitro sporulation nor spore germination was affected by curcumin. These results show the fungitoxic potential of turmeric and curcumin against $A$. solani.

Additional keywords: medicinal plant, turmeric, plant extract, tomato early blight, alternative plant disease control.
\end{abstract}

A cúrcuma (Curcuma longa L.) pertence à família Zingiberaceae, originária do sudeste asiático. O interesse econômico da cultura está baseado nos principais componentes qualitativos dos rizomas: corante curcumina e óleos essenciais. Utilizada já desde a antiguidade na medicina e gastronomia do oriente, a cúrcuma vem se tornando importante, atualmente, no combate a vários problemas de saúde humana, podendo-se destacar alguns efeitos de seus 
componentes como: antiinflamatório (Araújo \& Leon, 2001; Balasubramanyam et al., 2003), antioxidante (Scartezzini \& Speroni, 2000; Balasubramanyam et al., 2003) e atividades contra protozoários do gênero Leishmania (Araújo et al., 1999), bactérias de produtos alimentares (Uechi et al., 2000), fungos e leveduras dermatófitos como Trichophyton spp. e Candida spp. (Apisariyakul et al., 1995) e contra o vírus da imunodeficiência humana (Mazumder et al., 1995).

O uso de cúrcuma para o controle de fitopatógenos é relatado por Saju et al. (1998), que realizaram ensaio in vitro com a incorporação do óleo dessa planta em meio BDA nas concentrações de 1, 2, 3, 4 e 5\%. Os autores determinaram a atividade fungitóxica através da inibição do crescimento micelial, cujos valores foram de $100 \%$ para Colletotrichum gloeosporioides (Penz.) Penz. \& Sacc., Sphaceloma cardamomi Muthappa e Pestalotia palmarum Cooke para a concentração de $1 \%$ do óleo, e de $73 \%$ para Rhizoctonia solani J.G. Kühn, 53\% para Aspergillus sp. e 39\% para Fusarium sp. para a concentração de 5\% do óleo.

Foi verificado que o extrato aquoso de cúrcuma apresenta fungitoxicidade in vitro através da inibição do crescimento micelial em Fusarium udum (Berk.) Wollenw. (Raja \& Kurucheve, 1998) e reduz o crescimento micelial e a germinação in vitro de escleródios de Macrophomina phaseolina (Tassi) Goid. (Singh \& Raí, 2000).

Singh et al. (2002), estudando o efeito de óleos voláteis do rizoma de $C$. longa sobre vários fungos, verificaram que o óleo na concentração de 1000 ppm causou completa inibição do crescimento micelial de Colletotrichum falcatum Went e Fusarium moniliforme J. Sheld. e, na concentração de 2000 ppm, em Curvularia pallescens Boedijn, Aspergillus niger Thiegh. e Fusarium oxysporum Schlecht. Neste trabalho os autores também avaliaram os óleos de outras espécies de cúrcuma, como C. zedoaria (Christm.) Roscoe (rizomas) e C. aromatica Salisb (folhas), obtendo resultados semelhantes a 2000 e 3000 ppm, respectivamente.

Kuhn etal.(2006) estudaram o efeito do extrato aquoso de cúrcuma em Xanthomonas axonopodis pv. manihotis (Bondar) Vauterin, Hoste, Kersters \& Swings. In vitro, o extrato de cúrcuma apresentou ação bactericida dependendo da procedência dos rizomas de C. longa: houve inibição completa do crescimento da bactéria na concentração de $10 \%$ para o material proveniente de Mercedes/PR, enquanto que para cúrcuma de Jaboticabal/SP houve controle total a $15 \%$ e de Mara Rosa/GO a 20\%. A cúrcuma proveniente de Maringá PR não inibiu completamente o crescimento em nenhuma das concentrações utilizadas.

As ações citadas estão ligadas a uma série de compostos presentes norizoma da cúrcuma, como os fenólicos curcuminóides, que estão quimicamente relacionados ao principal componente do rizoma, a curcumina. Os principais curcuminóides com atividade biológica são: curcumina, desmetoxicurcumina, bisdemetoxicurcumina (Balasubramanyam et al., 2003), turmerona, metil-curcumina e curcuminato de sódio (Araújo \& Leon, 2001).

O objetivo deste trabalho foi avaliar a atividade fungitóxica in vitro dos extratos de cúrcuma e da curcumina contra Alternaria solani (Ellis \& G. Martin) L.R. Jones $\&$ Grout, como parte de um trabalho que visa ao controle alternativo da pinta preta do tomateiro.

Foram utilizados isolados obtidos a partir de lesões de plantas de tomateiro infectadas naturalmente com A. solani, coletadas no município de Marechal Cândido Rondon PR. O fungo foi cultivado em meio de cultura batata-dextrose-ágar (BDA) e incubado a $25^{\circ} \mathrm{C}$ e fotoperíodo de $12 \mathrm{~h}$.

Os rizomas de cúrcuma foram coletados na região de Mercedes PR e armazenados a $-20{ }^{\circ} \mathrm{C}$. Foram triturados com o auxílio de liquidificador, em caldo de batata, na dosagem de $200 \mathrm{~g}$ de rizoma por litro. O homogeneizado foi filtrado em gaze e papel de filtro Whatman $\mathrm{N}^{\circ} 1$ para eliminação de restos de células, constituindo um extrato líquido a $20 \%$. Este extrato foi diluído com caldo de batata para se obter extrato bruto (EB) a $1 \%, 5 \%$ e $10 \%$. Em todas as concentrações foram adicionados dextrose e ágar para completar o meio de cultura BDA, as quais foram autoclavadas a $120^{\circ} \mathrm{C}$ e 1 atm por 20 min. Foi utilizado um controle com o meio BDA puro.

A partir da curcumina, produto obtido de $C$. longa e disponível comercialmente, foi preparada uma solução estoque $(10 \mathrm{mg} / \mathrm{mL}$ de etanol absoluto), seguida de incorporação de alíquotas em meio de cultura BDA já autoclavado e semi-fundente para obter concentrações de $0,50,100,200$ e $400 \mathrm{mg} / \mathrm{L}$. Foram preparados um controle com o meio BDA puro e outro com etanol para determinar o efeito deste nos tratamentos com curcumina. $\mathrm{O}$ delineamento experimental foi inteiramente casualizado com três repetições.

Um disco de $7 \mathrm{~mm}$ de diâmetro contendo micélio de A. solani (retirado de colônia com 14 dias em BDA) foi repicado para o centro de cada placa, as quais foram vedadas com filme plástico e mantidas a $25^{\circ} \mathrm{C}$ e fotoperíodo de $12 \mathrm{~h}$. As avaliações foram realizadas através de medições do diâmetro das colônias (média de duas medidas diametralmente opostas) quando as colônias fúngicas atingiram $3 / 4$ da superfície da placa. A porcentagem de inibição do crescimento micelial foi calculada para cada dosagem em relação à testemunha. Os dados foram analisados estatisticamente pela análise de variância e análise de regressão a $5 \%$ de probabilidade. A concentração efetiva para inibição do crescimento micelial em $50 \%\left(\mathrm{EC}_{50}\right)$ foi estimada através da equação da regressão linear.

O teste de inibição da esporulação foi realizado ao término do teste de inibição de crescimento micelial, avaliando a esporulação do fungo em cada uma das placas usadas nesse teste. Para isto, foi preparada uma suspensão de esporos através da adição de $10 \mathrm{~mL}$ de água destilada na placa, raspagem da colônia com bastão de vidro e filtragem em gaze, sendo determinado o número de esporos $/ \mathrm{ml} \mathrm{com}$ auxílio de uma câmara de Neubauer ao microscópio ótico. Posteriormente determinou-se o número de esporos $/ \mathrm{cm}^{2}$ de colônia utilizando os resultados do teste de crescimento micelial. Os dados de inibição da esporulação, em 
porcentagem, foram analisados estatisticamente pela análise de variância, aplicando-se uma análise de regressão a 5\% de probabilidade.

Foi realizada esterilização por filtração dos EB de cúrcuma a 10 e $15 \%$ para verificar o efeito da autoclavagem nos extratos. Os rizomas de cúrcuma foram triturados em liquidificador, com caldo de batata, na dosagem de $150 \mathrm{~g} / \mathrm{L}$ constituindo um extrato líquido a $15 \%$. O homogeneizado foi filtrado em gaze e centrifugado a $6.500 \mathrm{~g}$ durante $20 \mathrm{~min}$ para eliminação de restos de células. $O$ sobrenadante foi filtrado em membrana Millipore $(0,45 \mu \mathrm{m}$ de diâmetro de poro) para reter as bactérias contaminantes. Ao extrato foram adicionados dextrose, ágar e caldo de batata autoclavados nas concentrações adequadas para se obter extratos a 10 e $15 \%$ de cúrcuma em meio de cultura BDA. Os testes de inibição do crescimento micelial e de inibição da esporulação foram realizados seguindo a metodologia acima relatada. Os dados de inibição, em porcentagem, foram analisados estatisticamente pela análise de variância, aplicando-se o teste de Tukey a 5\% de probabilidade para comparação das médias.

Para determinar a inibição da germinação de esporos, o ensaio foi instalado no delineamento inteiramente casualizado com três repetições por tratamento. Os tratamentos utilizados foram: extrato bruto autoclavado e não autoclavado nas concentrações de 0 (controle), 1, 5, $10 \mathrm{e}$ $20 \%$, curcumina nas concentrações de 0 (controle), 50, 100, 200 e $400 \mathrm{mg} / \mathrm{L}$.

Uma alíquota de $50 \mu \mathrm{L}$ da suspensão de esporos (2 x $10^{4}$ conídios $/ \mathrm{mL}$ ) e outra de $50 \mu \mathrm{L}$ das concentrações de extrato de cúrcuma e curcumina, corrigidas para se manter as concentrações citadas anteriormente, foram colocadas juntas em lâmina de microscopia revestida por uma camada delgada de ágar-água a 1\%. Essas lâminas foram incubadas em câmara úmida no escuro a $25{ }^{\circ} \mathrm{C}$ e a porcentagem de germinação determinada $12 \mathrm{~h}$ após. O esporo foi considerado germinado quando o comprimento de seu tubo germinativo foi maior ou igual ao menor diâmetro do esporo. Foram contados 300 esporos por tratamento.

Com o objetivo de avaliar o período necessário para a máxima germinação de esporos de $A$. solani, foi estabelecida uma curva de germinação de esporos, relacionando a porcentagem de germinação com o tempo necessário para tal. Uma alíquota de $80 \mu \mathrm{L}$ de suspensão de esporos $(2 \mathrm{x}$ $10^{4}$ conídios $/ \mathrm{mL}$ ), foi colocada em cada um dos recipientes (pocinhos) de uma placa usada no teste de ELISA. A paralisação da germinação foi com $10 \mu 1$ de azul algodão com lactofenol, no tempo 0 e a cada $2 \mathrm{~h}$ em cinco repetições (pocinhos), até $24 \mathrm{~h}$, totalizando 13 tempos de avaliação. Ao final, realizou-se a observação dos esporos germinados e não germinados ao microscópio ótico.

Os dados de inibição da germinação de esporos em porcentagem foram analisados estatisticamente pela análise de variância, aplicando-se uma análise de regressão a 5\% de probabilidade. Para análise, os dados foram previamente transformados em raiz quadrada de $(x+0,5)$.
A análise de variância do efeito das concentrações do extrato autoclavado de cúrcuma sobre o crescimento micelial de $A$. solani não foi significativa, ao contrário do efeito sobre a esporulação do fungo (Figura $1 \mathrm{~A}$ ). O máximo de inibição da esporulação $(78,6 \%)$ foi alcançado com a concentração de $20 \%$ de $\mathrm{EB}$ de cúrcuma, embora já tenha ocorrido uma inibição média de $46 \%$ com as menores concentrações testadas. Com relação ao efeito dos extratos brutos na germinação de esporos in vitro, verificou-se que os não autoclavados causaram inibições de até $15 \%$ (Figura $1 \mathrm{~B})$. Os extratos autoclavados não inibiram a germinação dos esporos (dados não mostrados), indicando a presença de algum composto termolábil.
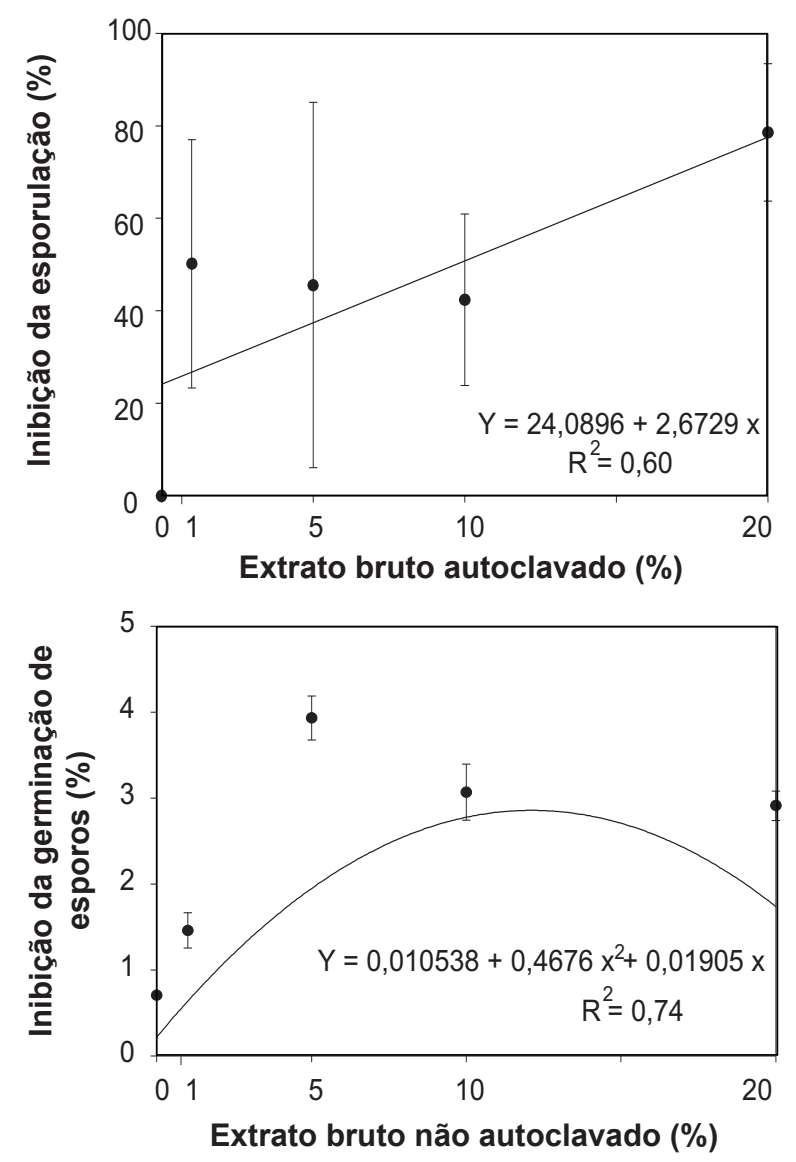

FIG. 1 - A. Efeito do extrato bruto de C. longa autoclavado e B. não autoclavado sobre a esporulação e a germinação de esporos de $A$. solani, respectivamente. Tratamentos controle: BDA e ágarágua $1 \%$ para os ensaios de esporulação e germinação de esporos, respectivamente. $\mathrm{Em} \mathrm{B}$, os dados foram transformados em raiz quadrada de $(\mathrm{x}+0,5)$.

A termoestabilidade dos compostos presentes em plantas medicinais está na dependência direta da espécie. Bonaldo et al. (2004) observaram que a germinação de conídios de Colletotrichum lagenaria (Pass.) Ellis \& Halst. foi inibida em mais de $90 \%$ na presença de extratos autoclavados de Eucalyptus citriodora Hooker, enquanto 
que para o extrato não autoclavado a inibição máxima foi de 75\%. Franzener et al. (2003) verificaram que o efeito antifúngico direto do extrato aquoso de Artemisia camphorata Vill. (cânfora) sobre a germinação de esporos de Bipolaris sorokiniana (Sacc.) Shoemaker foi grandemente afetado quando o mesmo foi autoclavado, pois não inibiu a germinação, enquanto que para os extratos não autoclavados a inibição foi de até $20 \%$.

Diante disso, com o objetivo de verificar um possível efeito deletério da autoclavagem nos extratos aquosos de cúrcuma, foram realizados testes de inibição de crescimento micelial e de esporulação utilizando extratos esterilizados por filtração. Para este fim, foram usadas as concentrações de $10 \%$ e $15 \%$ de extrato de cúrcuma. Houve inibição do crescimento micelial pelos EB não autoclavados, alcançando o nível de 38,2\% com EB $10 \%$. No caso da esporulação, a concentração de EB $10 \%$ inibiu $71,7 \%$, o que significou $29,3 \%$ a mais do que a inibição obtida com o EB autoclavado. Já na concentração de EB 15\%, a inibição do crescimento micelial foi de $23,2 \%$ e a inibição da esporulação foi de $87 \%$, valor este $8,5 \%$ mais alto do aquele obtido com EB 20\% autoclavado. Segundo estes resultados, a atividade antifúngica in vitro dos extratos de cúrcuma para A. solani estaria baseada fundamentalmente na inibição da esporulação, e em menor grau no crescimento micelial e na inibição da germinação de esporos.

Esses valores de inibição do crescimento micelial foram baixos quando comparados com trabalhos usando o óleo autoclavado de cúrcuma a 5\%, cujas inibições foram de até $100 \%$ para C. gloeosporioides, S. cardamoni e $P$. palmarum, embora para Fusarium sp. tenha sido de apenas 39\% (Saju et al., 1998).

$\mathrm{O}$ efeito das concentrações de curcumina sobre o crescimento micelial de $A$. solani in vitro pode ser observado na Figura 2. São apresentados também os dados de inibição do crescimento micelial descontando o efeito do etanol utilizado como solvente da curcumina. Houve inibição do crescimento micelial para doses crescentes de curcumina. Quando descontado o efeito do álcool, o máximo de inibição de crescimento micelial foi de $29,5 \%$ na maior concentração de curcumina testada $(400 \mathrm{mg} / \mathrm{L})$ (Figura 2 B). Provavelmente, poder-se-ia obter maior atividade antimicrobiana se fossem usadas maiores concentrações de curcumina, como no trabalho de Singh et al. (2002), no qual o óleo de cúrcuma a $1000 \mathrm{mg} / \mathrm{L}$ causou completa inibição do crescimento micelial de $C$. falcatum e F. moniliforme e a 2000 $\mathrm{mg} / \mathrm{L}$ em C. pallescens, A. niger e F. oxysporum. No entanto, no presente trabalho optou-se por usar concentrações de no máximo $400 \mathrm{mg} / \mathrm{L}$ para viabilizar futuras aplicações a campo de curcumina para controle da pinta preta do tomateiro. No presente trabalho a curcumina apresentou valores de $\mathrm{EC}_{50}$ estimados em $669,42 \mathrm{mg} / \mathrm{L}$ sobre o crescimento micelial de A. solani.

Em relação à ação da curcumina sobre a esporulação in vitro, o único efeito verificado foi devido ao etanol utilizado como solvente. Também não houve efeito da
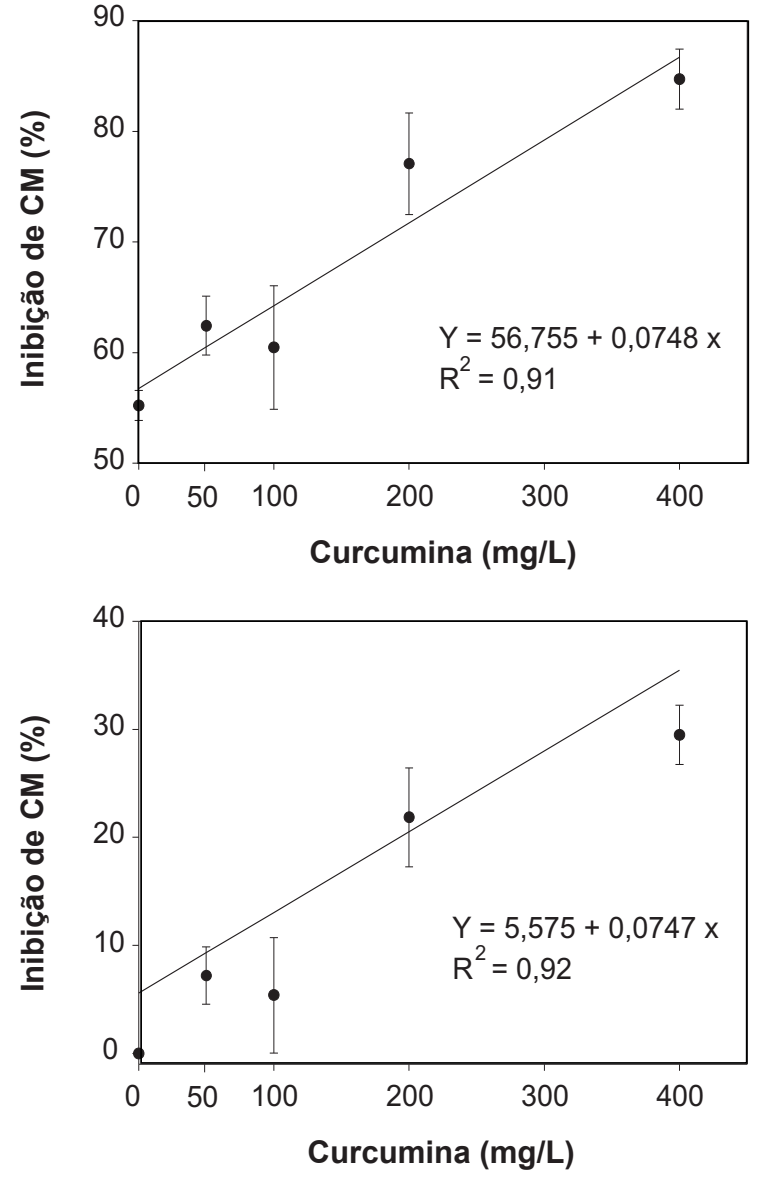

FIG. 2 - A. Efeito de curcumina sobre o crescimento micelial (CM) in vitro de $A$. solani. B. Estão representados os valores de inibição de crescimento micelial descontado o efeito do etanol utilizado para diluição da curcumina.

curcumina na germinação de esporos in vitro. Deste modo, se fosse considerado um ensaio in vivo, a curcumina não estaria interferindo na etapa de infecção (penetração do fungo na planta), mas por outros mecanismos em etapas posteriores do ciclo das relações patógeno-hospedeiro, como na colonização.

Esses resultados indicam o potencial antifúngico da cúrcuma e curcumina contra $A$. solani, justificando assim, a realização de ensaios em campo para verificar o efeito desses compostos no controle da doença pinta preta.

\section{AGRADECIMENTOS}

A primeira autora agradece à concessão de bolsa pela CAPES; JRS e KRFS à concessão de bolsa pelo CNPq.

\section{REFERÊNCIAS BIBLIOGRÁFICAS}

APISARIYAKUL,A., VANITTANAKOM, N. \& BUDDHASUKH, D. Antifungal activity of turmeric oil extracted from Curcuma longa (Zingiberaceae). Journal of Ethnopharmacology 49:163-169. 1995. 
ARAÚJO, C.A.C., ALEGRIO, L.V., CASTRO, D., LIMA, M.E.F., GOMES-CARDOSO, L. \& LEON, L.L. Studies on the effectiveness of diarylheptanoids derivatives against Leishmania amazonensis. Memórias do Instituto Oswaldo Cruz 94:791-794. 1999.

ARAÚJO, C.A.C. \& LEON, L.L. Biological activities of Curcuma longa L. Memórias do Instituto Oswaldo Cruz 96:723-728. 2001.

BALASUBRAMANYAM, M., KOTESWARI, A.A., KUMAR, R.S., MONICKARAJ, S.F., MAHESWARI, J.U. \& MOHAN, V. Curcumin-induced inhibition of cellular reactive oxygen species generation: Novel therapeutic implications. Journal of Biosciences 28:715-721. 2003.

BONALDO, S.M., SCHWAN-ESTRADA, K.R.F., STANGARLIN, J.R., TESSMANN, D.J. \& SCAPIM, C.A. Fungitoxicidade, atividade elicitora de fitoalexinas e proteção de pepino contra Colletotrichum lagenaria pelo extrato aquoso de Eucalyptus citriodora. Fitopatologia Brasileira 29:128-134. 2004.

FRANZENER, G., STANGARLIN, J.R., SCHWAN-ESTRADA, K.R.F. \& CRUZ, M.E.S. Atividade antifúngica e indução de resistência em trigo a Bipolaris sorokiniana por Artemisia camphorata. Acta Scientiarum 25:503-507. 2003.

KUHN, O.J., PORTZ, R.L., STANGARLIN, J.R., DEL ÁGUILA, R.M., SCHWAN-ESTRADA, K.R.F. \& FRANZENER, G. Efeito do extrato aquoso de cúrcuma (Curcuma longa) em Xanthomonas axonopodis pv. manihotis. Semina Ciências Agrárias 27:13-20. 2006.
MAZUMDER, A., RAGHAVAN, K., WEINSTEIN, J., KOHN, K.W. \& POMMIER, Y. Inhibition of human immunodeficiency virus type-1 integrase by curcumin. Biochemical Pharmacology 49:1165-1170. 1995.

RAJA, J. \& KURUCHEVE, V. Influence of plants extracts and buffalo urine on the growth and sclerotial germination of Macrophomina phaseolina. Indian Phytopathology 51:102-103. 1998.

SAJU, K.A., VENUGOPAL, M.N. \& MATHEW, M.J. Antifungal and insect-repellent activities of essential oil of turmeric (Curcuma longa L.). Current Science 75:660-662. 1998.

SCARTEZZINI, P. \& SPERONI, E. Review on some plants of Indian traditional medicine with antioxidant activity. Journal of Ethnopharmacology 71:23-43. 2000.

SINGH, G., SINGH, O.P. \& MAURYA, S. Chemical and biocidal investigations on essential oils of some Indian Curcuma species. Progress in Crystal Growth and Characterization of Materials 45: 75-81. 2002.

SINGH, R. \& RAI, B. Antifungal potential of some higher plants against Fusarium udum causing wilt disease of Cajanus cajan. Microbios 102:165-173. 2000.

UECHI, S., MIYAGI, Y., ISHIMINE, Y. \& HONGO, F. Antibacterial activity of essential oils from Curcuma sp. (Zingiberaceae) cultivated in Okinawa against foodborne pathogenic bacteria. Japanese Journal of Tropical Agriculture 44:138-140. 2000. 